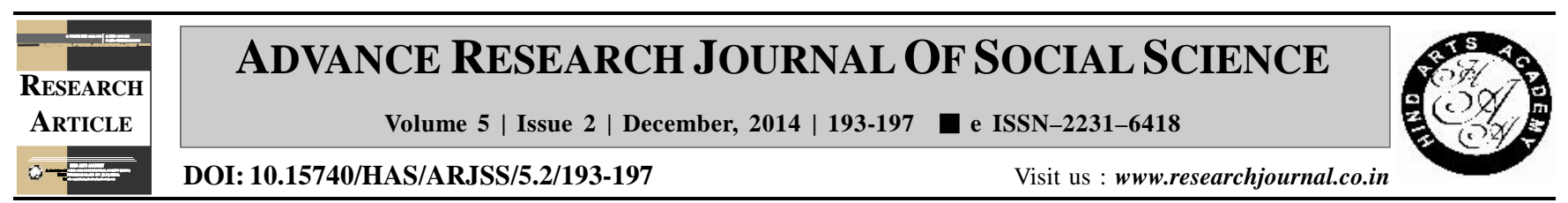

\title{
Tomato growers with their psychological variables, constraints and suggestions
}

Bhishman Sangada and Girish Deshmukh*

Department of Agricultural Extension, Junagadh Agricultural University, JUNAGADH (GUJARAT) INDIA

(Email: 251girish@gmail.com)

\section{ARTICLE INFO :}

$\begin{array}{lll}\text { Received } & : & 30.10 .2014 \\ \text { Revised } & : & 14.11 .2014 \\ \text { Accepted } & : & 27.11 .2014\end{array}$

\section{KEY WORDS :}

Economic motivation, Market orientation, Scientific orientation, Risk orientation, Cosmopoliteness

\section{HOW TO CITE THIS ARTICLE :}

Sangada, Bhishman and Deshmukh, Girish (2014). Tomato growers with their psychological variables, constraints and suggestions. Adv. Res. J. Soc. Sci., 5 (2) : 193-197.

*Author for correspondence

\begin{abstract}
Tomato is one of the most important protective foods because of its special nutritive value. It is one of the most versatile vegetable with wide usage in Indian culinary tradition. Tomatoes are used for soup, pickles, ketchup, puree, sauces and in many other ways. It is also used as a salad vegetable. Tomato has very few competitors in the value addition chain of processing. Tomato cultivation requires enough care right from nursery raising to post harvesting operations. Necessary package of practices must be followed for the better yield. It demands complete knowledge of methods and same must be followed by the tomato growers in right manner and at right time. The methodological procedure consisted of dependent and independent variables, setting and selection of the respondents, analysis of data and various statistical measures used to test the hypothesis. Majority $(82.50 \%)$ of the tomato growers were found with medium to high economic motivation. Vast majority $(79.17 \%)$ of the tomato growers had medium level of market orientation. Two-third $(66.66 \%)$ of the tomato growers had medium scientific orientation. Over whelming majority $(95.00 \%)$ of the tomato growers had medium to high level of risk orientation. Two-third $(65.00 \%)$ of the tomato growers were found with low level of cosmopoliteness.
\end{abstract}

